\title{
SURVEY, HBIM AND CONSERVATION PLAN OF A MONUMENTAL BUILDING DAMAGED BY EARTHQUAKE
}

\author{
D. Oreni ${ }^{\text {a }}$, R. Brumana ${ }^{\text {a }}$, S. Della Torre ${ }^{\text {a }}$, F. Banfi ${ }^{\text {b }}$ \\ a Politecnico di Milano, Department of architecture, built environment and construction engineering, via Ponzio 31, 20133 Milano, \\ Italy (daniela.oreni, raffaella.brumana, stefano.dellatorre)@polimi.it \\ b PhD Internship at the Carleton Immersive Media Studio (CIMS), Carleton Universisty, Ottawa, Canada (fabrizio.banfi@polimi.it)
}

\author{
Commission VI, WG VI/4
}

KEY WORDS: survey, structural geometry, earthquake, HBIM, conservation project

\begin{abstract}
:
Surveying a monumental building damaged by the earthquake means to analyse its geometries, the structural elements, the connection still exist between the different parts, in order to define its state of conservation, to make structural analysis and to plan a proper project of restoration, consolidation, seismic improvement or addition of new elements. The survey of structural geometry represents the first necessary moment of building' knowledge investigation, to be performed after the securing of the building by the Firefighters or Civil Protection. How and by which instruments the geometric analysis are conducted depends on many factors, not always exclusively on the will of the experts involved in the restoration project, but more often dictated by political, technical, social or economic needs. The accurate geometrical survey is referred as fundamental operation even by national Directive for evaluation and earthquake risk reduction of cultural heritage (GU n. 24 - 29/01/2008 and 2011 updates), which defines guidelines for preventive interventions on built heritage in order to make the structures less vulnerable in case of earthquake.

Nowadays, the wide use of tools and accurate surveying techniques makes it possible to achieve an adequate level of accuracy of information related to the buildings, overcoming the difficulties due to accessibility of the damaged structures.

The geometrical survey of the Basilica of Santa Maria di Collemaggio in L'Aquila, was made by Politecnico di Milano starting from 2013, within the project "Ripartire da Collemaggio" (http:/www.ungiornoacollemaggio.it/content/2027), financed by Eniservizi. The basilica, an important symbol for the community of L'Aquila, was gravely damaged by the earthquake of $6^{\text {th }}$ April 2009. The objective of Eni was to turn the restoration of the building in a re-birth moment for all the community. The knowledge step was aimed to plan a restoration project able of returning the basilica to a safe and full use. In the two years knowledge investigation steps (geometric survey, historical and stratigraphic analysis, materials investigation, structures and soils examination, in situ tests and numerical elaborations) was involved an interdisciplinary group of researchers from various Italian universities, Politecnico di Milano, Università La Sapienza in Rome and the University of L'Aquila, called to provide a scientific advice to the Soprintendenza ai Beni Architettonici e Paesaggistici per l'Abruzzo, project manager of the restoration step. In early 2016 the yard of restoration was opened and it is still on-going.
\end{abstract}

The geometrical survey of the basilica was aim to investigate, measure and represent the exact geometry of the damaged structures and their three-dimensional complexity; the survey was planned choosing the tools and methods most appropriate in relation with the accessibility and safety of the structures, the operating ranges of acquisition and the level of detail required by the analysis and the project. This meant to integrate global and local surveying techniques, in order to cross relate data derived by different tools and to make the graphical restitution of the entire monumental complex: topography, laser scanning, photogrammetry, but also hands on instruments, at a scale of representation from 1:1 to 1:50. The laser scanner survey, registered in the accurate geomatics network, responded to the need to punctually investigate and interpret the geometrical configuration of different spaces of the Basilica, as well as its structural articulation, enabling a series of horizontal and vertical profiles, as requested by various experts involved in the diagnostic steps.

HBIM model (Historical Building Information Modeling) of the entire basilica was primarily intended as a tool for stereotomic description of the building and its parts, following the constructive logic of each structural element; then it was used as a support tool for the restoration simulation, project, management and yard. To perform the division of the building in its constructive elements, sometimes it has been used stratigraphic methodologies and instruments of analysis. The entirety of the geometric and structural complexity of the basilica, was guarantee using sophisticated 3D software and drawing complex entities, integrated and stored in the parametric BIM logic. This process has allowed to accurately and timely represent the geometry of the structural elements, of the areas characterized by crushing, empties, variations of the masonry sections and out of plumbs.

It is on the pillars of the nave that was focused the attention of survey: the will to preserve as much as possible the existing structures, in their material authenticity, required a careful analysis of each individual stone element of each pillar, investigated in its geometry, texture and state of conservation. The aim of the project was to ward a complete replacement of the pillars, preferring instead a removing and replacing intervention of only of the stone ashlars completely deteriorated and no longer recoverable, considering the question of structural safety as fundamental. The HBIM of the basilica had the primary function of connecting into one virtual space all the available data; that model has also been made as a tool for managing the restoration yard, supporting the computation of stone to buy, quarry and grossly slot, saving time on site.

Different and complementary skills were used in every knowledge and restoration steps; the accurate analysis of the structures made it possible to plan a consolidation and restoration project as close as possible to the structural conception of the existing building, adding only the new structural elements necessary to increase the resistance and to guarantee the safety of the structures, also in case of new earthquake. The Italian Codice dei Beni culturali e del paesaggio (DL n.42/2004), at paragraph 4 of art. 29, states that the restoration includes structural improvements. For the restoration of Collemaggio the solutions chosen were the ones able to be more 
effective and, at the same time, less invasive, more respectful as possible of the sacredness of the architecture, its highest historical significance, the authenticity of the material and its cultural significance.

The main principles and criteria of restoration were: maximum correspondence of conservation doctrine, with a focus on improving the structural characteristics compared to the seismic risk; exemplarity of the management practices of the restoration process; exemplarity of innovative techniques; transparency of all processes and accurate communication of cultural and scientific content. Despite of some inevitable compromises, the detailed knowledge of the building allowed to design punctual interventions, inserting new structures where the oldest were collapsed and consolidating damaged elements, in order to improve the global safety of the building but without modifying substantially the structural conception of the stratified basilica.

\section{INTRODUCTION}

\subsection{Geometrical survey of monumental structures damaged by earthquake}

Surveying a monumental building damaged by the earthquake means to analyse its geometries, the structural elements, the connection still existing between the different parts, in order to define its state of conservation, to make structural analysis and to plan a proper project of conservation, consolidation, seismic improvement or addition of new elements.

The survey of constructive geometry represents the first necessary moment of building's knowledge investigation, to be performed after the securing of the building. How and by which instruments the geometric analysis are conducted depends on many factors, not always exclusively on the will of the experts involved in the restoration project, but more often dictated by political, technical, social or economic needs.

The accurate geometrical survey is referred as fundamental operation even by national Directive for evaluation and earthquake risk reduction of cultural heritage (G.U. 29/01/2008 n. 24 and 2011 updates), which defines guidelines for preventive interventions on built heritage in order to make the structures less vulnerable in case of earthquake.

Nowadays, the wide use of tools and accurate surveying techniques makes it possible to achieve an adequate level of information related to the buildings, overcoming also the difficulties due to accessibility of the damaged structures.

\section{THE BASILICA OF SANTA MARIA DI COLLEMAGGIO IN L'AQUILA: FROM SURVEY TO CONSERVATION PLAN}

\subsection{Survey and HBIM of the church}

The geometrical survey of the Basilica of Santa Maria di Collemaggio in L'Aquila, was made by Politecnico di Milano starting from 2013, within the project "Ripartire da Collemaggio", financed by Eniservizi

(http://www.ungiornoacollemaggio.it/content/2027).

The Basilica, an important symbol for the community of L'Aquila, was gravely damaged by the earthquake of $6^{\text {th }}$ April 2009. The objective of Eni was to turn the restoration of the building in a re-birth moment for all the community.

The diagnostic investigation was aimed to plan a conservation project able of returning the Basilica to a safe and full use. In the two years knowledge investigation steps (geometric survey, historical and stratigraphic analysis, materials investigation, structures and soils examination, in situ tests and numerical elaborations, etc.) it was involved an interdisciplinary group of researchers from various Italian universities, Politecnico di Milano, Università La Sapienza in Rome and the University of L'Aquila, called to provide a scientific advice to the Soprintendenza ai Beni Architettonici e Paesaggistici per l'Abruzzo, the project manager of the restoration of the Basilica. In early 2016 the yard of restoration was opened and it is still ongoing.
The geometrical survey was aim to investigate, measure and represent the exact geometry of the damaged structures and their three-dimensional complexity; the survey was planned choosing the tools and methods most appropriate in relation with the accessibility and safety of the different parts, the operating ranges of acquisition and the level of detail required by the analysis and the project. This meant to integrate global and local surveying techniques, in order to cross relate data derived by different tools and to make the graphical restitution of the entire monumental complex: topography, laser scanning, photogrammetry, but also hands on instruments, at a scale of representation from 1:1 to 1:50 (Oreni, 2014). The laser scanner survey, registered in the accurate geomatic network, responded to the need to punctually investigate and interpret the geometrical configuration of different spaces of the Basilica, as well as its structural articulation, enabling a series of horizontal and vertical profiles, as requested by the different experts involved in the diagnostic analysis (Figure 1).

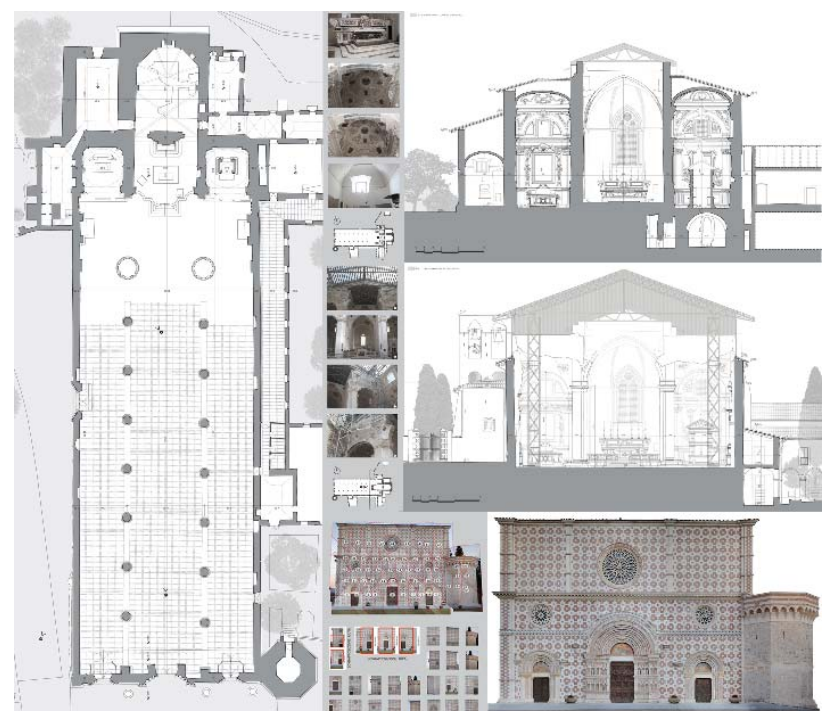

Figure 1. $2 \mathrm{~d}$ drawings and orthophoto of the main front at scale $1: 50$.

The HBIM (Historical Building Information Modelling) of the building was created in order to provide a data exchange tool to all the experts; an instrument that could be easily implemented and updated with the new information revealed during the conservation works. HBIM was chosen despite of the difficulties related to the issue of geometric modelling of complex and irregular construction elements.

HBIM model of the entire Basilica was primarily intended as an instrument for a stereotomic description of the building and its parts, following the constructive logic of each element. To perform the division of the building in its constructive elements, sometimes it has been used stratigraphic methodologies and instruments of analysis. The entirety of the geometric and structural complexity of the Basilica, was guarantee using sophisticated 3D software and drawing complex entities, 
integrated and stored in the parametric BIM logic. This process has allowed to accurately and timely represent the geometry of the areas characterized by crushing, empties, variations of the masonry sections and out of plumbs.

The parametric model of the church, divided in its structural elements (Figure 2), was created at increasing LOD (Level Of Development) levels of development and detail, depending on the information available during the different diagnostic steps.

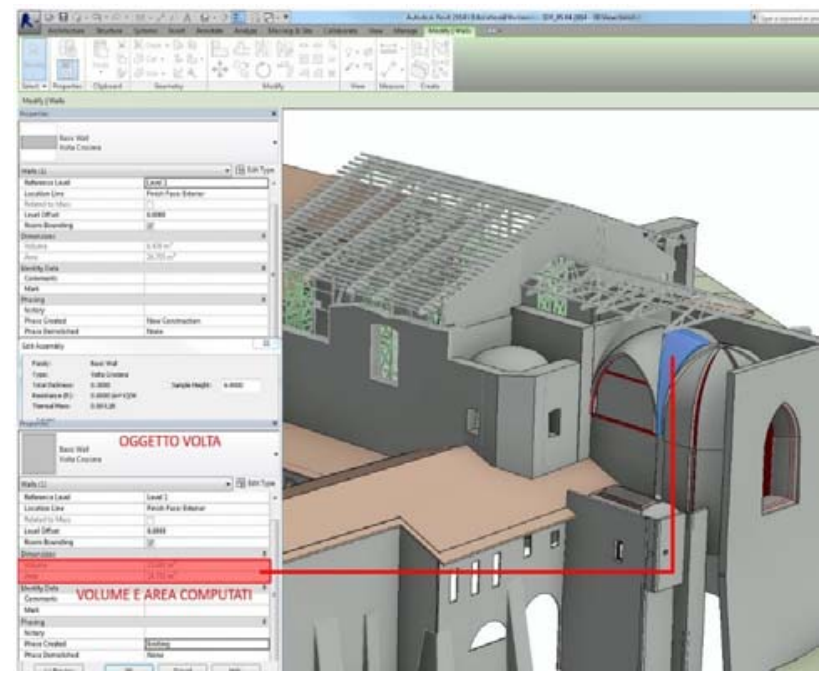

Figure 2. HBIM of the Basilica, divided in structural elements: wall, floor, roof, pillar, vault, door, window, etc.

\subsection{Restoration project of the Basilica}

Different and complementary skills were used in every knowledge and restoration steps; the accurate analysis of the structures made it possible to plan a consolidation and restoration project as close as possible to the structural conception of the existing building, adding only the new elements necessary to increase the resistance and to guarantee the safety of the structures, also in case of a new earthquake.

The Italian Codice dei Beni culturali e del paesaggio (DL n.42/2004), at paragraph 4 of art. 29 , states that the restoration includes structural improvements. For the restoration of Collemaggio, the solutions chosen were the ones able to be more effective and, at the same time, less invasive, more respectful as possible of the sacredness of the architecture, of its highest historical significance, of the authenticity of the material and of its cultural significance. The main principles and criteria of restoration plan were: i. Maximum correspondence of conservation doctrine, with a focus on improving the structural characteristics compared to the seismic risk; ii. Model of restoration management practices; iii. Model of innovative techniques; iv. Transparency of all processes and accurate communication of cultural and scientific content and results.

Despite of some inevitable compromises, the detailed knowledge of the building allowed to design punctual interventions, inserting new structures, where the older ones have collapsed, and consolidating damaged elements, in order to improve the global safety of the building but without modifying substantially the structural conception of the stratified Basilica.

The restoration solution, officially approved in 2014 and now in the final phase of construction (2017), involves the reconstruction of the transect area and the conservation of the other structural and decorative elements. The central dome is not rebuilt and the wooden roof is now visible; two barrel vaults cover the transept. This internal design choice is reflected on the outside with a cover almost continuous (Figure 3 ).

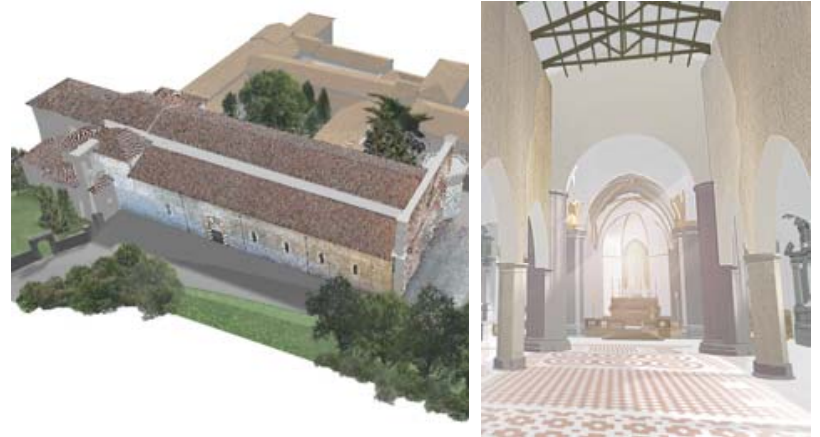

Figure 3. 3D external and internal model views of one of the different solution proposed during the conservation plan of the building.

The new cover is constructed in order to reduce the overall stresses to the structures and any future risks of collapse in the naves.

The two central lobed columns are rebuilt in reinforced concrete and with an external stone facing, reusing blocks recovered after the collapse of the dome. The arches between the two columns are reconstructed, together with the last pointed arches of the nave and the cross vault of the apse area, with pointed arches. The upper parts of the lateral masonry of the building are rebuilt, while the methods of consolidation of the other portions are various and depends on the local conditions of instability.

The nave columns are interested by a delicate restoration phase and two different interventions were planned and partially completed, depending from the state of conservation of each element: i. Substitution (pillars n. 02-03-07-10-11-15) of only the irreparably stone ashlars (to punctually verify during the construction step); ii. Operations of disassemble and reassemble of the columns (n. 04-05-06-12-13-14), with the replacement of the elements irremediably compromised. Metal pins are inserted to connect the broken but recoverable ashlars, and high resistance mortar is injected in the joints and in the nucleus of each column.

\subsection{HBIM to support the Conservation Plan and Process}

The decision to build a BIM model of the Basilica was carried out with awareness about a great potential offered by this tool, both in terms of planning and evaluation of the entire knowledge and conservation process of an historical building, and in terms of its management and future maintenance. Nowadays the most advanced experiments concern the integration and interoperability between the different phases of the process (planning, design, construction, documentation, management, checking and monitoring). In particular, the BIM technologies allow the communication between data coming from different software, allowing a greater exchange of information between many actors (Della Torre, 2014).

The Title XI of Italian D.P.R. 207/2010 requires producing a maintenance plan for all the restoration work on historical and artistic buildings. Declining this document in accordance with the methodological indications of Planned Conservation (D. L. $22 / 01 / 2004$, n. 42), the tool developed for the yard of Collemaggio is the "Conservation Plan" (Della Torre, 2015). In this logic, the final scientific and technical report (prescribed by art. 250 of the Italian DPR 207/2010 Regulations) on cultural and scientific results obtained with the restoration, represents the first update of the conservation plan of the building, fundamental for the future intervention and maintenance programs.

The Conservation Plan of the Basilica is arranged according to different levels of detail of the information, in order to guarantee an efficient data management structure and an effective application of the plan. The Plan is implementable and updating 
in future, inputting new information on the conservation status of the elements or parts of the building, reviewing the timing of planned activities or simply supplementing the document with the results of new inspections.

The possibility to link the Conservation Plan to the BIM of the Basilica allows: i. To identify the technological elements in their proper spatial position, thus fully comprehend the mutual relationships between the components of the building and between these and the surrounding environment; ii. To enrich the conservation plan with information deriving from BIM. Similarly, to BIM, the construction of the Conservation Plan has necessitated the building's division into its constructive elements, categorized for technological classes; every structural element is identified with a unique code and described in detail in a Plan table (Figure 4). The item "constructive element" allows connecting HBIM model and Conservation Plan database: the singular table of the Plan are connected to the corresponding geometrical elements trough a URL path.

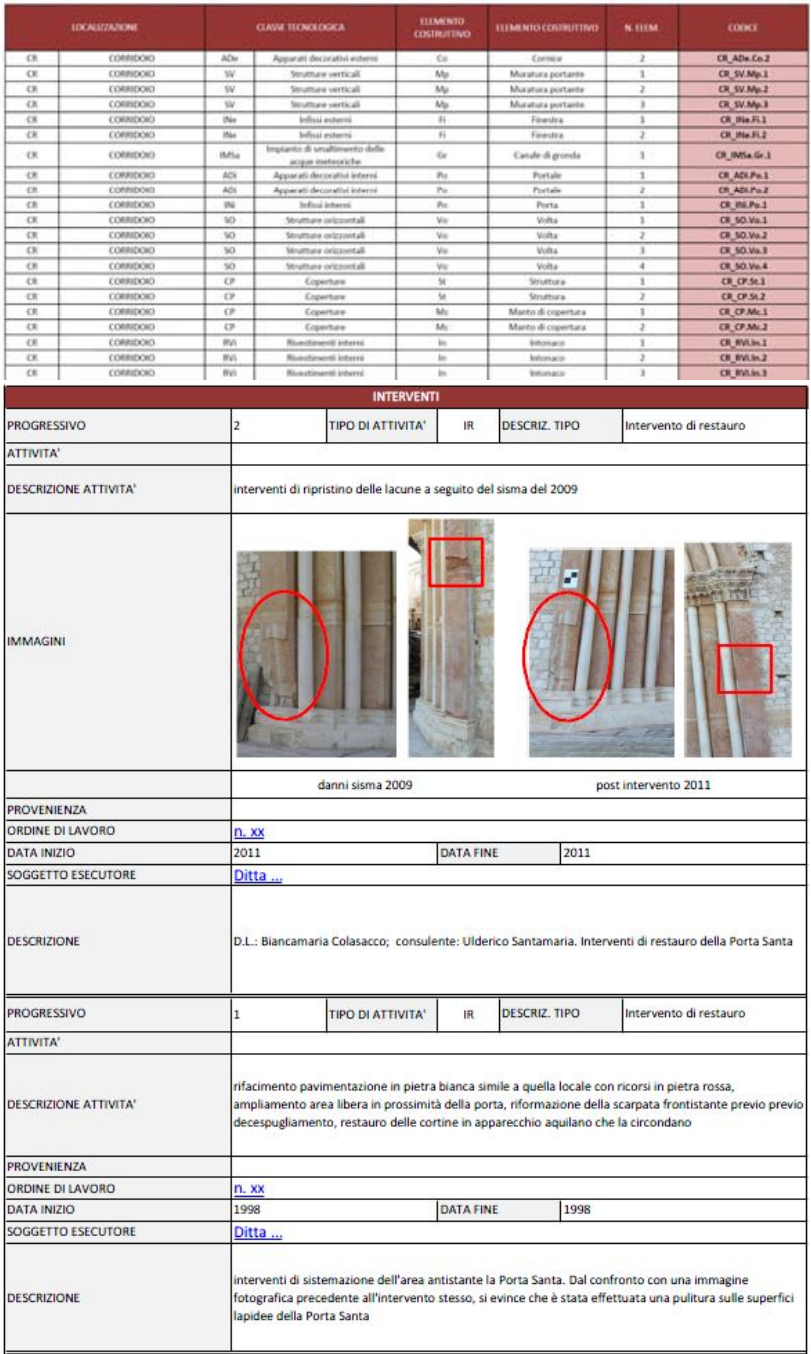

Figure 4. Codification of constructive elements in the Conservation Plan (above) and an example of Plan table (below).

Consequently, HBIM and Conservation Plan could be used by all the different actors involved in the restoration site and in the future maintenance of the Basilica: from the project supervisor, that could record the restoration data, till to the proper of the church, that could better manage and identify the priorities of the necessary actions, organizing and scheduling the operations of the long-term preservation process.

\section{THE STONE COLUMNS OF THE NAVE: FROM SURVEY TO THEIR CONSERVATION}

\subsection{Geometrical survey of stone ashlars and HBIM}

During diagnostic investigation (2013 - 2014), using 3D laser scanner data it has been possible to derive the exact geometry of only the columns of the nave, while it was not always possible to analyse the shape of the capitals, covered by a protective wooden boards. Similarly, laser scanner and photogrammetric data were unusable for the recognition of the ashlars division, because of the dense network of wooden boards, on four of the eight faces of the pillars, and because of the horizontal provisional fabric hooping. It was therefore essential to proceed with a hands on survey of each pillar, in order to draw the shape and disposition of every stone element (Figure 5).

A detailed mapping of the crack pattern and the position of the broken or degraded ashlars were performed, in order to plan the different conservation activities: replacing, integration or consolidation. It was evident that the number of the elements to completely substitute will be added or changed during the restoration site; it will be especially necessary to deep investigate all the areas interested by past restoration interventions, where the cracks were cover using a filling mortars made with the powder of the same stone, hiding any other broken ashlar.

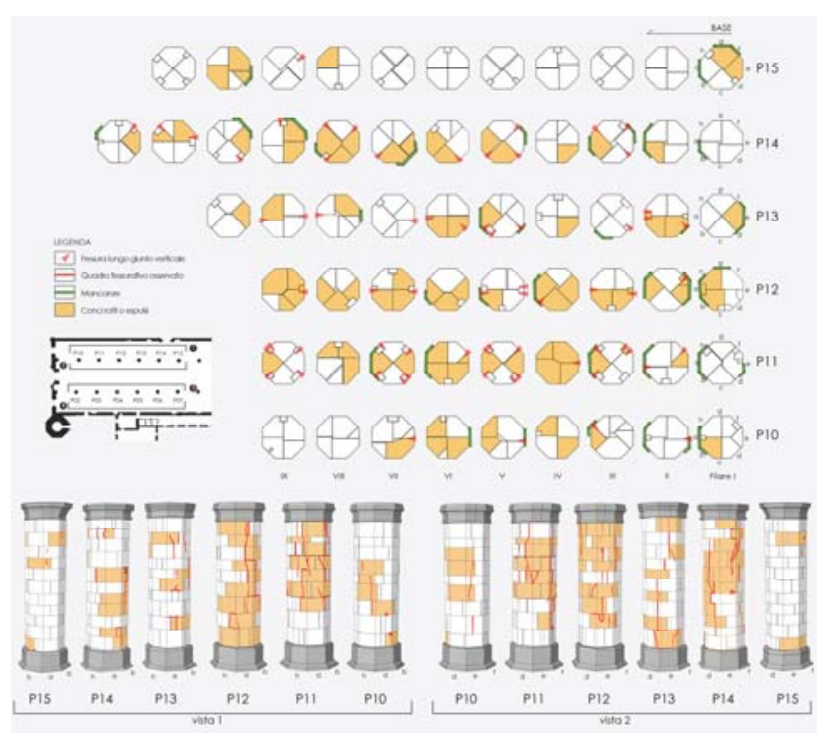

Figure 5. 2D and 3D drawings of the left nave's columns and their stone ashlars. In yellow color, the broken ashlars (diagnostic analysis).

The geometrical and material analysis conducted on the pillars, showed a generalized diffusion of patch elements, characterized only by a hypothesized thickness, presumably variable from one zone to another.

Similarly, it was possible only to make constructive suppositions about the size of the mortar internal core of the pillars (partially visible only in column n. 6), definitely variable in position and dimension.

The geometric survey recognition of the ashlars of every pillar were finally drawn in 2D (plan and fronts), and in 3D, using BIM technology (Oreni, 2017). 


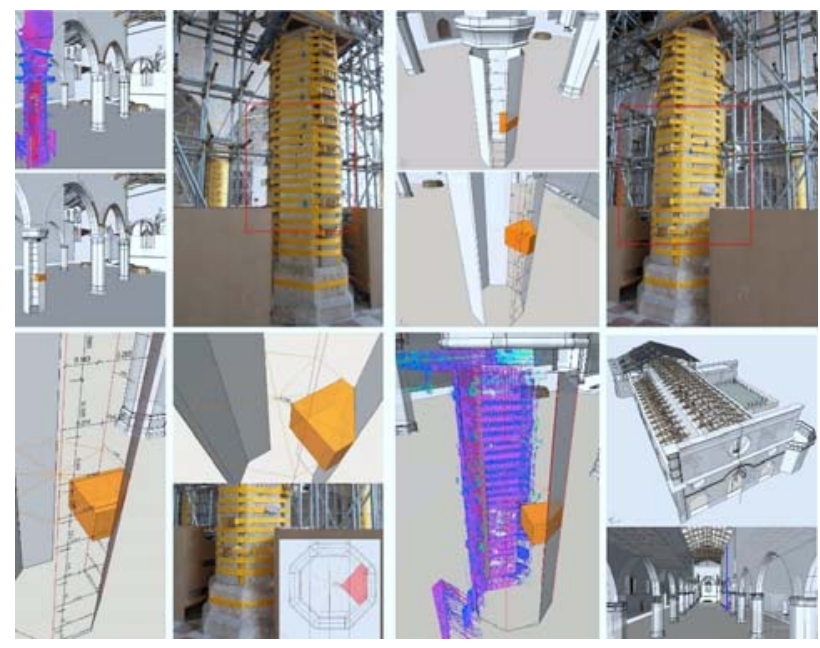

Figure 6. HBIM model from laser scanner data.

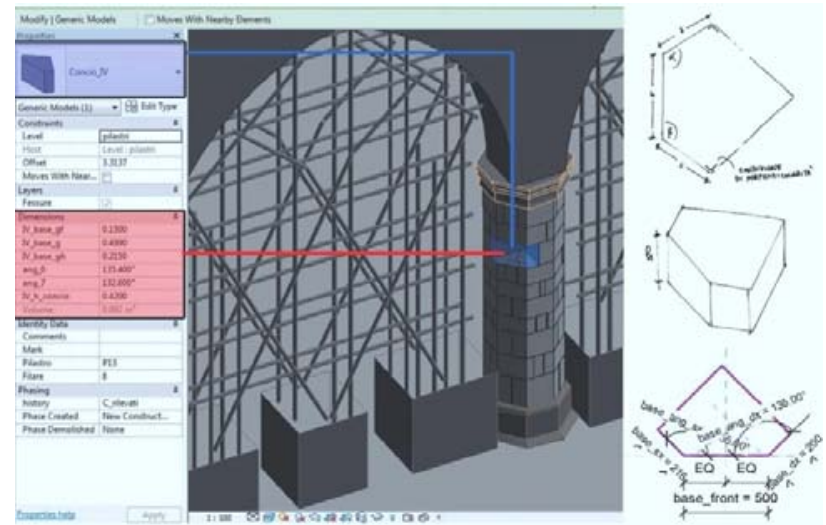

Figure 7. HBM of octagonal stone pillar n. 6 of the nave. On the right the hands on survey of the only ashlar completely visible.

\subsection{Comparison between the geometrical data on columns and the information derived from the restoration activities}

Once started the restoration of the columns (2016), it was possible to gradually compare the detected or deducted geometric information during diagnostic investigation with the information derived from the restoration activities, especially about the central pillars, completely disassemble, as expected from the project.

The first phase of the restoration of the columns consisted in the removing of the vertical loads, by inserting progressively metal temporary structures under the two relevant arches. This operation allowed proceeding with local intervention of stone ashlar replacement or with the complete disassemble operation of the columns.

First were disassemble, starting from the upper part, numbered and reassemble on the floor, the ashlars of the central pillars (P04-05-06-12-13-14), the most stressed by the seismic actions and extremely degraded (Crespi, 2016). This operation allowed to verify the exact geometry of the stone elements, to evaluate the material and thickness of the central core (Figure 8), to recognize the broken elements (not visible from outside) and to refine and rectify the drawings made during the diagnostic phase (Figure 9).

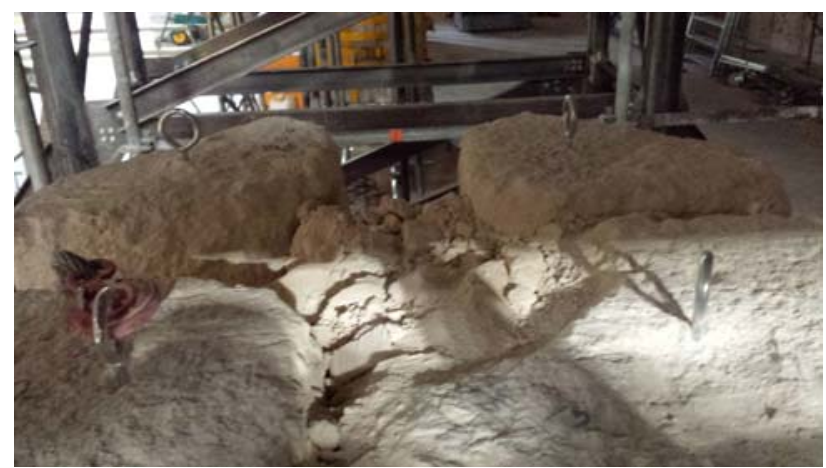

Figure 8. Top images of a pillar during the disassemble step; in the centre, the irregular mortar core of the column.

The comparison between all the information gathered has permitted to validate the survey method used in the diagnostic phase and the results obtained, both in terms of geometric analysis and of volume's stone to replace (approximately $50 \%$ of the total volume of the columns). In the complex, infect, it was registered a good correspondence between the geometry of the blocks detected with the real ones, albeit with some expected and in some cases also important differences. The major differences are linked to the failure detection of the broken stone elements in the inner part, along fracture lines not visible from the outside, or covered by temporary wooden structures.

Regarding the patch stone elements, mostly due to restoration work performed by the Superintendent Moretti in the ' 70 s of the twentieth century, it was recorded a substantially their limited thickness, so as assumed in the diagnostic phase.

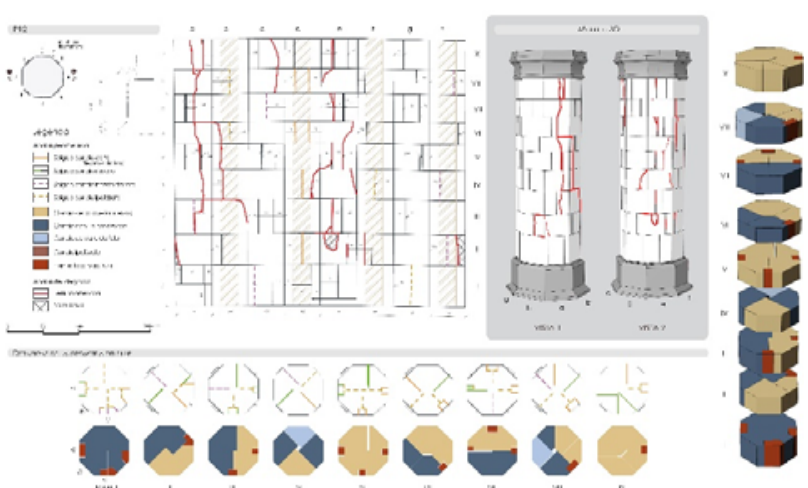

Figure 9. Pillar n. 12: drawings made during diagnostic phase.

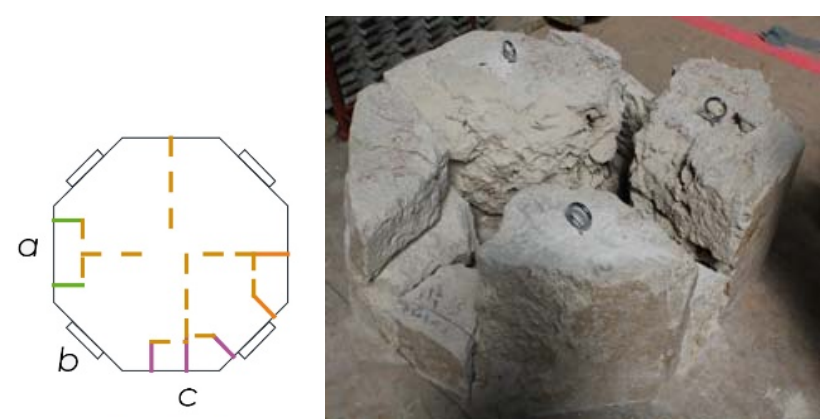

Figure 10. Pillar n. 12 - row I. On the left, diagnostic drawing; on the right the ashlars disassemble and reassemble on the floor of the Basilica. 


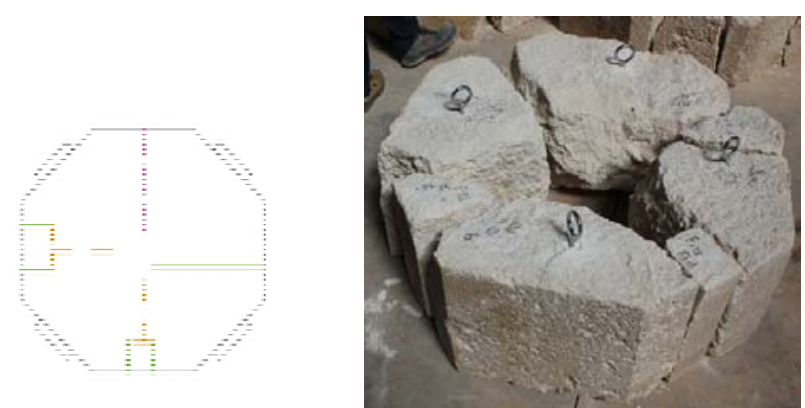

Figure 11. Pillar n. 12 - row III. On the left, diagnostic drawing; on the right the ashlars disassemble and reassemble on the floor.
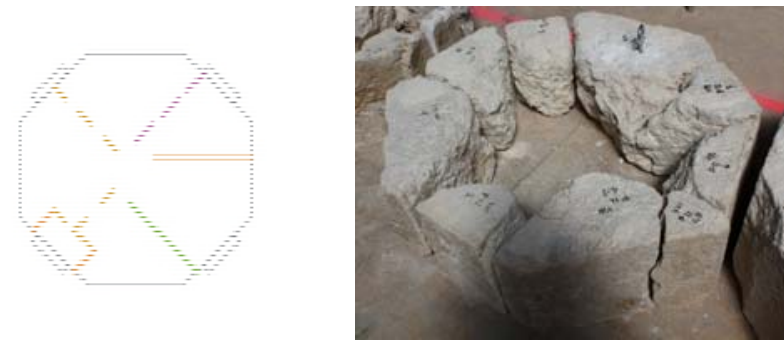

Figure 12. Pillar n. 12 - row VIII. On the left, diagnostic drawing; on the right, the ashlars disassemble and reassemble.

The operation of disassemble of the central columns of the nave has showed a big difference between the shapes of the core of each row, depending from the stone ashlar dimension and disposition. In some rows the central core occupies until the 50\% of the total area, compromising the mechanical characteristics of all the elements. The material filling the core is the so-called "incoherent mortar", poor of aggregates, similar to the mortar analysed in the pillar n. 6, during the diagnostic phase.

Throughout the restoration activities, it was possible to recover some stone elements, in some case using metal connection or paste, that were considered seriously damaged in diagnostic step; in that case, infect, their external condition did not reflect the inner one (Figure 13), therefore it was possible to recover them.

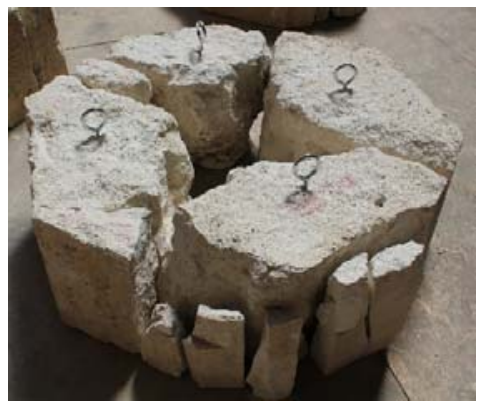

Figure 13. Pillar n. 11 - row 1 . It is evident the external deterioration of the stone, in good condition in the inner part.

\section{CONCLUSION}

The restoration of the Basilica of Collemaggio was an important opportunity for methodological comparison, collaboration and exchange of information between various experts involved in diagnostic analysis, conservation and consolidation planning on that monumental historical building damaged by the earthquake. The possibility to have an accurate survey of the damaged structures and a detailed BIM model is a great opportunity, not only in terms of knowledge enrichment, but also in terms of production of a project that could be as close as possible to the real condition of the building, developing ad hoc solutions. Although it is obvious that having available an accurate survey or HBIM model is not sufficient to automatically get a good conservation project; instead, the final project is often the result of a complex discussion, debate and confront among many different actors involved in the planning activities, not always in agreement on the singular intervention choices.

The HBIM of the Basilica could be used for many different purposes: i. To store and easily access to data collected; ii., To evaluate the different project solutions, during the intervention planning; iii. To support the final design; iv. To manage the restoration site; v. To support programmed conservation and future maintenance of the historical building. Nevertheless, many difficulties remain in using BIM for conservation project, linked both to the complication in modelling articulated and irregular geometric elements, and for the administrators and construction enterprises, in working within complex 3D modelling environments.

\section{ACKNOWLEDGEMENTS}

Authors would like to thank arch. Antonello Garofalo (Soprintendenza ai Beni Architettonici e Paesaggistici per l'Abruzzo), ing. Paolo Strada (Eniservizi), Prof. Alberto Franchi and Eng. Pietro Crespi (Politecnico di Milano) for the images taken during the restoration phase.

\section{REFERENCES}

Bartolomucci, C., 2004. Santa Maria di Collemaggio. Interpretazione critica e problemi di conservazione. Palombi Editore, Roma.

Crespi, P. G., Franchi, A., Giordano, N., Scamardo, M. A., Ronca, P., 2016. Structural analysis of stone masonry columns of the Basilica S. Maria di Collemaggio. In: Engineering structures, 129, pp.81-90.

Della Torre, S., 2014. ICT per il miglioramento del processo conservativo. Nardini Editore, Firenze.

Della Torre, S., 2015. Shaping tools for Built Heritage Conservation: from architectural design to program and management. Learning from Distretti culturali. Van Balen, K., Vandesande A., Community Involvement in Heritage (Reflections on Cultural Heritage Theories and Practices). Garant, Antwerp, pp. 93-102.

D. L. $22 / 01 / 2004$, n. 42 . Codice dei beni culturali e del paesaggio.

D.P.R. 5/10/2010, n. 207. Regolamento di esecuzione ed attuazione del D.L. 12/04/2006, n. 163.

G.U. 29/01/2008, n. 24 (and 2011 updates). Direttiva per la valutazione e la riduzione del rischio sismico del patrimonio culturale con riferimento alle norme tecniche per le costruzioni.

Oreni, D., Brumana, R., Della Torre, S., Banfi, F., Barazzetti, L., Previtali, M., 2014. Survey turned into HBIM: the restoration and the work involved concerning the Basilica di Collemaggio after the earthquake (L'Aquila). In: ISPRS Annals of the Photogrammetry, Remote Sensing and Spatial Information Sciences, II/5, pp. 267- 273.

Oreni, D., Brumana, R., 2014. "Restituire" la Basilica di Collemaggio a L'Aquila: geometrie, strutture e modelli per il progetto di conservazione. Italian survey \& international experience. Unione Italiana Disegno, Parma, pp. 409-420. 